See Article page $\mathrm{XXX}$.

\section{Commentary: Intraoperative neuromonitoring: FAST to FASTER response to neurologic complication}

Yihan Lin, MD, Muhammad Aftab, MD, and T. Brett Reece, MD

Intraoperative neuromonitoring for both arch surgery and descending/thoracoabdominal interventions remains debated. While opponents complain about the common false-positive findings, the authors from Pittsburgh describe the predictive value of intraoperative neurophysiologic monitoring (IONM) during aortic arch surgery with hypothermic circulatory arrest. ${ }^{1}$ Importantly, the results demonstrated that patients with IONM changes had an increased mortality and adverse neurologic events, with somatosensory-evoked potentials being more sensitive than electroencephalogram in predicting neurologic events.

Although these conclusions seem intuitive, they are important in optimizing the Achilles heel of neurologic complications in aortic surgery. A complaint with monitoring historically has been that the understanding of these changes does not change the care of the patient. However, this is no longer the case. The authors describe several actions that could be taken if IONM was abnormal, seen in Figure 3. These include immediate intraoperative changes (increase cerebral perfusion, scan the carotid arteries using ultrasonography, evaluate the anastomoses for possible kinking), interventions after removal of the crossclamp, such as to increase arterial pulsatility or increase perfusion pressure, and postoperative steps including immediate

\footnotetext{
From the Department of Cardiothoracic Surgery, University of Colorado, Aurora, Colo.

Disclosures: The authors reported no conflicts of interest.

The Journal policy requires editors and reviewers to disclose conflicts of interest and to decline handling or reviewing manuscripts for which they may have a conflict of interest. The editors and reviewers of this article have no conflicts of interest.

Received for publication Aug 22, 2021; revisions received Aug 22, 2021; accepted for publication Aug 23, 2021.

Address for reprints: T. Brett Reece, MD, Department of Cardiothoracic Surgery, University of Colorado, 12631 E 17th Ave, Room 5401, Mail Stop C-291, Aurora, CO 80045 (E-mail: brett.reece@ucdenver.edu).

J Thorac Cardiovasc Surg 2021;

$0022-5223 / \$ 36.00$

Copyright (c) 2021 by The American Association for Thoracic Surgery

https://doi.org/10.1016/j.jtcvs.2021.08.054
}

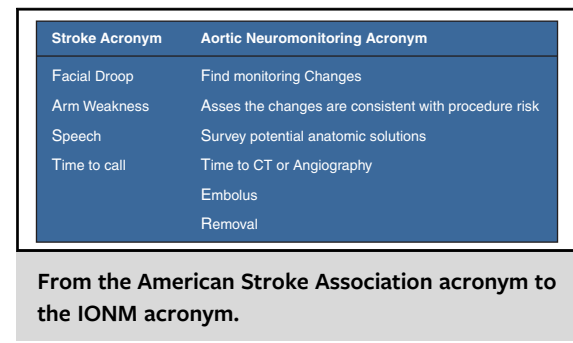

\section{CENTRAL MESSAGE \\ Although controversial, intrao- perative neuromonitoring has the potential to facilitate stroke treatment in aortic surgery.}

computed tomography angiography of head and neck to determine whether any neurointervention could be indicated. This can be taken a step further to include on table angiograms and potential embolectomy, which we have done in a couple of cases that were already in the hybrid room.

We applaud the authors for their work in furthering the ability to intervene on abnormal IONM in these complex cases. Ultimately, the role of IONM is to direct real-time changes with immediate interventions to improve patient outcomes. While this continues to progress, this study does help us get closer to the goal of eliminating stroke in these at risk operations. More studies in this area will be helpful in minimizing false positives as well as determining reliable thresholds for interventions such as on table cerebral imaging. As hybrid suites become more commonplace, this will most certainly become a reality in the future of aortic arch interventions.

\section{Reference}

1. Sultan I, Brown JA, Serna-Gallegos D, Thirumala PD, Balzer JR, Paras S, et al Intraoperative neurophysiologic monitoring during aortic arch surgery. J Thorac Cardiovasc Surg. July 22, 2021 [Epub ahead of print]. 